\title{
Study on Adaptability of RFID Tags in Concrete Structure Engineering by Experiment
}

\author{
Dongsheng $\mathrm{SHI}^{1, a^{*}}$, Liang $\mathrm{ZHANG}^{1, b}$ \\ ${ }^{1}$ School of Civil Engineering, Inner Mongolia University of Technology, Hohhot, 010051, China \\ aemail: shids@imut.edu.cn, bemail: 450722905@qq.com, *corresponding author
}

Keywords: RFID tag, concrete structure engineering, adaptability, communication distance

\begin{abstract}
In this paper, the adaptability of RFID tags in concrete structure engineering was studied by experiment. 10 types of common RFID tags that were used to distribution management and identity recognition coming from market were tested in this experiment. As results, the communication distances of RFID tags in reinforced concrete specimens were much shorter than communication distances of RFID tags in free space of laboratory, and the message could not even be read from a few RFID tags. In other words, common RFID tags that used to distribution management and identity recognition coming from market are not suitable for concrete structure engineering. In order to use RFID technology in concrete structure engineering, it is necessary that special RFID tag need to be developed.
\end{abstract}

\section{Introduction}

RFID (Radio Frequency Identification) is an automatic identification technology, it is similar to bar code label, the information of management objects is stored in the RFID tag that attached to the object by digital encoding, and the information can be transmitted to the RFID reader by radio waves. RFID system has lots of advantages, including a large amount of stored information, long life, anti-jamming capability etc. Now, the RFID technology mainly were used in physical distribution management, identity recognition etc.

The construction industry has encountered some problems in the development. One of the more important problems is that construction engineering information management was backward. The construction engineering information includes project information, design information, building materials information, and quality information and so on. The volume of construction engineering information is huge, and is stored in variety of paper documents in design institute, in construction company, in management department of government and so on. There were a lot of engineering claims and disputes which were caused by error messages or information losses. Therefore, the RFID technology can save construction engineering information in RFID tags that were fixed in construction members, and the information can easily be read and written. The RFID technology will improve the level of construction information management. It began from 1990s that the research about RFID system was used in field of construction information management. In 1995, Jaselskis E.J. of Iowa State University first proposed the concept about using RFID technology in construction engineering [1]. And in the early 2000s the experiment about construction project information management in the application of RFID Technology was tested by Professor Jaselskis E.J. [2]. In recent years, some scholars outside the United States also began to study feasibility about using RFID technology in construction project information management, and some research papers were published [3,4].

As the construction industry is more special than other industries, there are some problems that RFID were used in construction engineering $[5,6]$. One of these problems is adaptability of RFID tags in construction engineering. The RFID tag is sophisticated electronic devices, environment of construction site is complex, especially, metals and water of construction engineering can influence radio signal transmission on the RFID system. In this paper, the adaptability of using RFID tag system in concrete structure engineering will be explored by experiment. 


\section{Experiment}

In this experiment, 10 types of common RFID tags that were used to distribution management and identity recognition coming from market were tested. These RFID tags were shown in Fig. 1, and specific parameters of these RFID tags were list in Table 1. The RFID reader is handheld reader and is shown in Fig. 2. The handheld RFID reader was made by Shenzhen Foxconn Technology Co., Ltd, and specifications are list in Table 2.

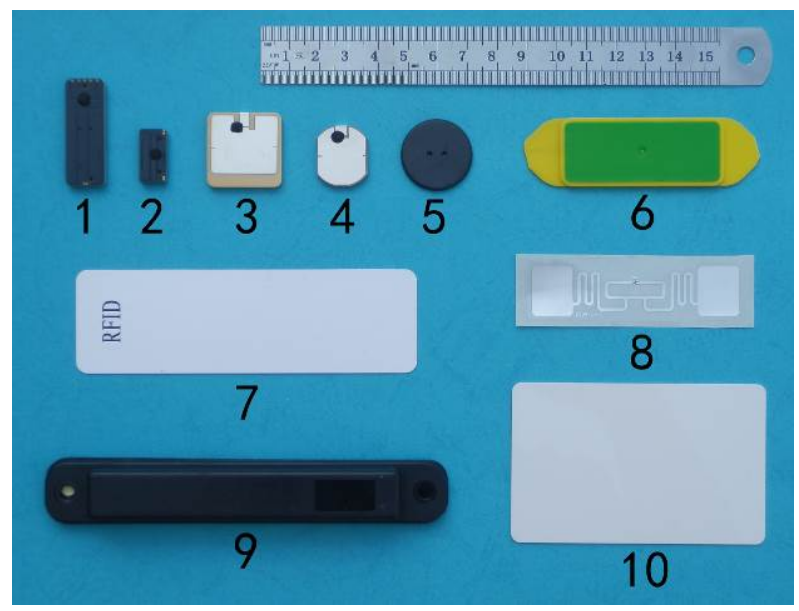

Fig.1 Ten Types of RFID Tags

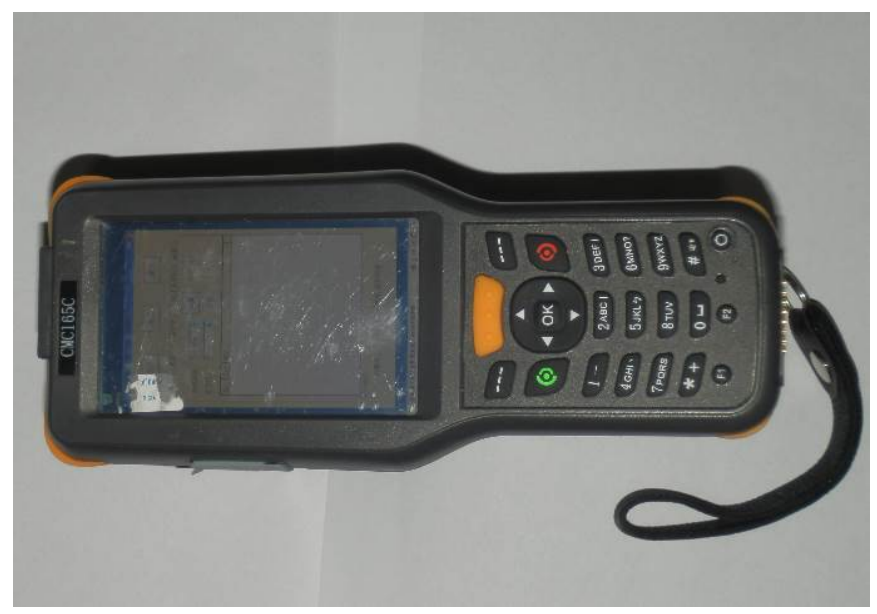

Fig. 2 RFID Handheld Reader

Table 1 Parameters of RFID tags

\begin{tabular}{rllcc}
\hline No. & \multicolumn{1}{c}{ Package } & \multicolumn{1}{c}{ Antenna Type } & Frequency & Protection rating \\
\hline 1 & Bakelite base board & Double coupled dipole antenna & $915 \mathrm{MHz}$ & IP65 \\
2 & Bakelite base board & Double coupled dipole antenna & $920 \mathrm{MHz}$ & IP65 \\
3 & Ceramics substrate & Double microstrip antenna & $915 \mathrm{MHz}$ & IP65 \\
4 & Ceramics substrate & Double microstrip antenna & $920 \mathrm{MHz}$ & IP65 \\
5 & Sealing plastic buttons & Folded dipole antenna & $905 \mathrm{MHz}$ & IP67 \\
6 & Flexible plastic packaging & Large double dipole antenna & $915 \mathrm{MHz}$ & IP65 \\
7 & Waterproof paper packaging & Printed dipole antenna & $915 \mathrm{MHz}$ & --- \\
8 & Film printing packaging & Printed dipole antenna & $920 \mathrm{MHz}$ & -- \\
9 & Plastic cassette packaging & Large double dipole antenna & $915 \mathrm{MHz}$ & IP67 \\
10 & Plastic card packaging & Printed dipole antenna & $915 \mathrm{MHz}$ & IP65 \\
\hline
\end{tabular}

Table 2 Specifications of RFID Handheld Reader

\begin{tabular}{ll}
\hline \multicolumn{1}{c}{ Item } & \multicolumn{1}{c}{ Content } \\
\hline Operating System & WINCE 6.0 \\
CPU & High-speed ARM platform, clocked 800MHz \\
Memory & 512MB DDR2 SDRAM \\
WiFi Module & WLAN 802.11 b/g \\
RFID Module & HF(Optional), UHF, 2.4G \\
UHF Operating Frequency & $902 \sim 928 \mathrm{MHz}($ Customize within: 860 960MHz) \\
2.4G Operating Frequency & $2.4 \sim 2.5 \mathrm{GHz}$ \\
UHF Protocol & EPC C1 G2 (ISO18000-6C) \\
\hline
\end{tabular}


Specimens that were the carrier of RFID tag were a series of reinforced concrete wall. And these reinforced concrete wall specimens were made of concrete, and profile steel, the strength grade of concrete was C30, the steel bar was HRB400 grade deformed steel bar, the profile steel was Q235 type steel hot-rolled low carbon steel, in here, concrete, steel bar and profile steel were according to industry standards of China. The thickness of reinforced concrete wall specimens was $200 \mathrm{~mm}$, concrete cover thickness of steel bar was $25 \mathrm{~mm}$ and concrete cover thickness of profile steel was $50 \mathrm{~mm}$.

About RFID tags fixed in reinforced concrete wall specimen, at first, surface of profile steel was cleaned by sandpaper, second, RFID tag was pasted by cyanoacrylate speed dry glue, and last, RFID tag was sealed off by high performance two-component epoxy resin glue, the epoxy resin glue could protect RFID tag to destruction from outside. Samples of RFID tags fixed in reinforced concrete wall specimen are shown in Fig. 3.

After RFID tag was stuck by epoxy resin glue, cured it for 24 hours. Then, concrete support template was fixed and pouring concrete. After reinforced concrete wall specimen forming, these specimens were cured for 28 days in standard concrete curing laboratory.
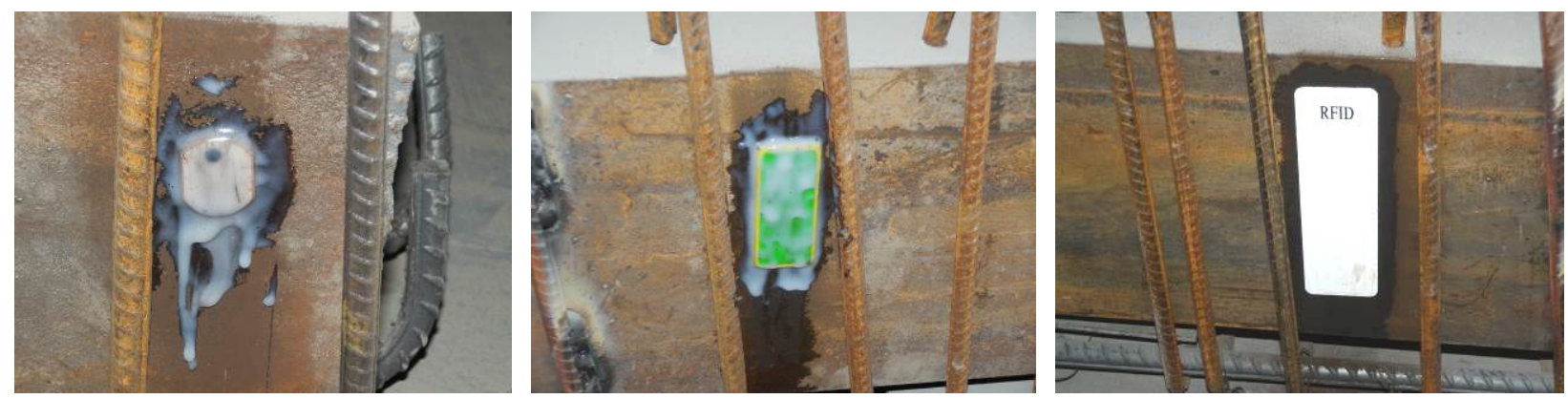

Fig. 3 Samples of RFID tags fixed in reinforced concrete wall specimen

\section{Results}

The test about adaptability of RFID tags in concrete was divided into two parts, one was that tested the maximum distance about reading and writing information from RFID tags in reinforced concrete wall specimen, other one was that tested the maximum distance about reading and writing information from RFID tags in free space of laboratory. The results of test are listed in Table 3.

Table 3 Distance about reading and writing of RFID tags (Units: $\mathrm{m}$ )

\begin{tabular}{lccccccccccc}
\hline No. & 1 & 2 & 3 & 4 & 5 & 6 & 7 & 8 & 9 & 10 \\
\hline Dist. of reading in free space & 1.15 & 1.35 & 2.54 & 3.12 & 1.28 & 1.40 & 4.60 & 2.51 & 1.56 & 5.10 \\
Dist. of writing in free space & 0.89 & 0.93 & 1.87 & 1.91 & 0.89 & 1.02 & 2.95 & 1.79 & 1.01 & 3.23 \\
Dist. of reading in specimen & 0.37 & 0.45 & 0.85 & 1.35 & --- & 0.43 & --- & --- & 0.52 & --- \\
Dist. of writing in specimen & 0.29 & 0.41 & 0.63 & 0.97 & --- & 0.32 & --- & --- & 0.37 & --- \\
\hline
\end{tabular}

Note: “---” means that message cannot be read and written from RFID tags.

From data of Table 3, it is known that distances of reading about RFID tags in free space were over $1 \mathrm{~m}$ and maximum is $4.60 \mathrm{~m}$ of No.6 RFID tag, and distances of writing in free space are shorter than distances of reading. Distances of writing are $61.2 \sim 77.4 \%$ of distances of reading, the average value is $68.7 \%$ in free space of laboratory. Either distances of reading or distances of writing about RFID tags in reinforced concrete wall specimens are much shorter than distances of reading about RFID tags in free space of laboratory, the distances in concrete specimens are almost no more than $1 \mathrm{~m}$ except that reading distance of No.4 RFID tag is up to $1 \mathrm{~m}$ and it is $1.30 \mathrm{~m}$. The distances difference between reading and writing in reinforced concrete wall specimens are less than in free space, distances of writing are $71.1 \sim 91.1 \%$ of distances of reading, the average value is $76.8 \%$ in specimens. 
In this experiment, the message cannot be read and written from No.7, 8, 10 RFID tags that used printed dipole antenna and No.5 RFID tag that used folded dipole antenna, on other words, these RFID tags that used printed dipole and folded dipole antenna cannot fit to be used in reinforced concrete engineering. Although RFID tags using double coupled dipole antenna and double microstrip antenna can be used in concrete, but the communication distance is much shorter than in free space. Therefore, the common RFID tags that were used to distribution management and identity recognition coming from market are not suitable for concrete structure engineering, and it is necessary that special RFID tag need to be developed in order to using RFID technology in concrete construction engineering.

\section{Conclusions}

(1) Distances of communication about RFID tags in reinforced concrete specimens are much shorter than distances of communication about RFID tags in free space of laboratory. And the message cannot even be read from a few RFID tags in reinforced concrete specimens.

(2) The distance difference between reading and writing in reinforced concrete specimen is less than in free space of laboratory.

(3) The common RFID tags used to distribution management and identity recognition coming from market are not suitable for concrete structure engineering. In order to use RFID technology in concrete structure engineering, it is necessary that special RFID tag need to be developed.

\section{Acknowledgement}

The authors are grateful to the financial support by the Science Foundation of Inner Mongolia (No. 2014MS510) and the National Science Foundation of China (No. 51268041). In addition, the authors also acknowledge the help of China Scholarship Council and the finance coming from the Cao Yuan Ying Cai Project of Inner Mongolia government of the P. R. China.

\section{References}

[1] E.J. Jaselskis, M.R. Anderson, C.T. Jahren, Y. Rodriguez, S. Njos: Radio-frequency identification applications in construction industry, Journal of Construction Engineering and Management, 121(2), pp.189-196, ASCE, 1995

[2] E.J. Jaselskis, T. Ei-Misalami: Implementing radio frequency identification in the construction process ; Journal of Construction Engineering and Management [J], 129(6), pp.680-688, 2003

[3] Elghamrawy, Tarek; Boukamp, Frank: Managing construction information using RFID-based semantic contexts; Automation in Construction, Vol.19, No.8, pp.1056-1066, Dec. 2010

[4] Mariotti C., Orecchini G.; Virili M., Alimenti F., Roselli, L.: RFID tag antenna embedded in concrete structures for construction industry; 6th European Conference on Antennas and Propagation, EuCAP 2012, pp.3469-3472, Mar. 26-30, 2012

[5] Chun-Ta Tzeng a, Yi-chang Chiang a, Che-ming Chiang a, Chi-ming Lai: Combination of radio frequency identification (RFID) and field verification tests of interior decorating materials; Automation in Construction 18 (2008) , pp.16 - 23, Elsevier, 2008

[6] Jeong Seung-Hwan, Son Hae-Won: UH RFID tag antenna for embedded use in a concrete floor; IEEE Antennas and Wireless Propagation Letters, Vol.10(2011), pp.1158-1161, 2011 